\title{
Visual Pathway Disorder
}

National Cancer Institute

\section{Source}

National Cancer Institute. Visual Pathway Disorder. NCI Thesaurus. Code C35342.

A disorder of the neural pathway from the optic nerve to the visual cortex. 